\title{
LOS AÑOS DESCONOCIDOS DE MAUD BONNEAUD
}

\author{
Ángeles Alemán Gómez* \\ Universidad de Las Palmas de Gran Canaria
}

\section{RESUMEN}

La figura de Maud Westerdahl (1921-1991) es conocida desde 1955, cuando se instala en Tenerife y adopta el apellido de su segundo marido, el crítico de arte Eduardo Westerdahl. Sin embargo, los años anteriores de su vida, significativos e importantes en relación con el Surrealismo, quedaron olvidados por deseo propio y por la sociedad de la época. La investigación de su historia nos ha conducido a descubrir la importancia real de esta mujer extraordinaria, artista, crítica de arte y activista cultural, usando textos publicados e inéditos de la propia Maud, su correspondencia privada con personajes de la época como André Breton y otros documentos inéditos.

Palabras clave: literatura, Surrealismo, correspondencia, André Breton.

\section{THE UNKNOWN YEARS OF MAUD BONNEAUD}

\section{Abstract}

Maud Westerdahl (1921-1991) was quite well known since 1955, when she got married with her second husband, the critic of Art Eduardo Westerdahl, and moved to Tenerife. However, the former years of her life, which were significant and important in relation to Surrealism, were forgotten, probably by her own decision and because of the society of this time. The research done about Maud Bonneaud has given us the image of an extraordinary woman, critic of art and artist. We have too discovered the correspondence she had with some of the most relevant people of her time, such as André Breton, and well as another unpublished texts.

KeYwords: Litterature, Surrealism, Correspondence, André Breton. 


\section{A MODO DE INTRODUCCIÓN: EL ENIGMA MAUD}

En 1959, Julián Gállego escribió en un artículo sobre Óscar Domínguez: «QQué más decir de un pintor? Que se casó con una joven estudiante del Limosín, Maud Bonneaud; se divorciaron en 1952, sin hijos»" ${ }^{1}$. Gállego nombraba a esta joven; sin embargo, años más tarde Eduardo Westerdahl, a la sazón segundo marido de Maud, publicó un estudio sobre el artista surrealista canario en el que escribió:

En 1948 (Óscar Domínguez) adquirió la nacionalidad francesa, puesto que su vida y su obra se desarrollaban en Francia. Se había casado con una universitaria francesa, integrada en el movimiento surrealista, la cual se divorció de él años más tarde ${ }^{2}$.

Maud Bonneaud había desaparecido del relato biográfico de Óscar Domínguez de forma voluntaria; ella, Maud Westerdahl, «el más importante apoyo con que el surrealismo francés cuenta en Tenerife» ${ }^{3}$, había decidido que sus años anteriores como Maud Bonneaud permanecieran en el olvido. Quizás fue una decisión tomada por prudencia en una época sombría, pero su memoria, la memoria de quien fue Maud Bonneaud, merece ser rescatada, y eso es lo que nos hemos propuesto en este artículo, basado en su vida entre 1939 y 1955.

\section{POITIERS 1939. ENCUENTRO DE ANDRÉ BRETON Y MAUD BONNEAUD}

Desde el 3 de septiembre de 1939 hasta el 22 de junio de 1940, en Francia se vivió una situación extraña, conocida como drôle de guerre. Desde entonces hasta la firma del tratado de Vichy, el ejército francés fue movilizado. El oficial médico André Breton fue destinado a la Escuela de Aviación de Poitiers, hospedándose en un pequeño hotel en el que, durante un apagón, conoció a una joven estudiante, Maud Bonneaud, que «acababa de leer con sus amigos Ubu Rey de Alfred Jarry. Encontrarse con Breton cuando volvió la luz le indicó que el destino había preparado el encuentro» ${ }^{4}$.

* Profesora titular de Historia del Arte. Universidad de Las Palmas de Gran Canaria. Edificio de Humanidades. C/ Pérez del Toro, n. ${ }^{\circ}$ 1. C.P. 35003, Las Palmas de Gran Canaria. e-mail: angelesaleman@ulpgc.es.

${ }^{1}$ Gállego, Julián: «La pintura de Óscar Domínguez», Anuario de Estudios Atlánticos, n. ${ }^{\circ}$ 5, Las Palmas de Gran Canaria, 1959, p. 125

2 Westerdahl, Eduardo: Óscar Domínguez, Barcelona, 1968, p. 15. 1975), p. 161.

3 Pérez Minik, Domingo: Facción española surrealista de Tenerife, Tenerife, 1995 (1. ${ }^{\mathrm{a}} \mathrm{ed}$.

${ }^{4}$ Sullivan, Rosemary: Villa Air-Bel. World War II, Escape and a House in Marseille, Nueva York, 2006, p. 13. 
Maud Bonneaud, que había nacido en 1921 en Limoges ${ }^{5}$, era estudiante de Letras, y la admiración por el Surrealismo ya aparecía entre sus preferencias literarias e incluso en su manera de confiarse al azar. Pero el encuentro con Breton fue lo que decididamente cambió su vida. Breton fue para ella «un viento arrasando las arenas de la normalidad, un tifón devastando la pequeña isla de la vida confortable. Incluso en su desolación era hermoso» ${ }^{6}$. Años más tarde, al escribir sobre este encuentro diría:

En un pequeño hotel, donde vivía, se hospedaba también un misterioso militar melenudo, de extraños modales versallescos: era nada menos que el llamado Papa del Surrealismo, André Breton: se aburría en este rol de movilizado para él insoportable. Hicimos amistad y empezó a pasar a diario las veladas con mis amigos y yo. Nos habló durante meses: influencia imborrable en una mente joven y abierta. Hablaba de su viaje a Tenerife, de Freud, de magia, de Rimbaud, de Sade, de Picasso, etc. Nos daba sus revistas, hoy piezas de museo. A la llegada de las tropas alemanas se marchó dejándome en depósito cajas de sus colecciones aztecas. Marchó a Nueva York y no le volví a ver sino después de la guerra?

Aunque Maud no volvió a ver a Breton hasta años más tarde, se preocupó de hacerle llegar sus cajas y de guardar algunos de sus objetos en Limoges. En la carta que aquél le escribió desde Martigues, fechada la víspera de salir rumbo a Marsella, le comentaba:

Les deux petites caisses sont fort bien arrivées: j'y pensé, voulez vous encore avoir la bonté de m'enumerer sommairement ce qui vous paraît rester d'un peu important à Limoges (en deux ou trois lignes) ${ }^{8}$.

La amistad con el creador del Surrealismo se había forjado de manera sólida y Breton, en su misiva, le confesaba su angustia:

Nous restons, par cet assez beau temps, assez désagréablement suspendus entre New York et Paris, à la merci d'un renouvellement de passeports et de visas divers, à vrai dire sans grand espoir?

${ }_{5}^{5}$ Madeleine Anette Bonneaud nació el 4 de enero de 1921 en Limoges, como consta en el acta del Ayuntamiento de Limoges. El sobrenombre Maud surgió en 1936 durante una estancia escolar en Londres. octubre, 1943.

${ }^{6}$ Bonneaud, Maud: «Notes sur une rencontre», Proffil Litteraire de la France, n. ${ }^{\circ}$ 15, Niza,

7 Gaviño de Franchy, Carlos: «Maud (Bonneaud) Westerdahl. Biocronología», en Ed. Castro, Fernando y Ángel Mollá: Maud y Eduardo Westerdahl. 2 miradas sobre el siglo 20, Las Palmas de Gran Canaria, 2005, 45.

${ }^{8}$ Breton, André: Lettre à Maud 13 octubre 1940, Marseille: Villa Bel Air, 1989, cortesía de Yale University Library, 6.

${ }^{9}$ Breton, André: Lettre à Maud 13 octubre 1940, ibid., 6-7. 


\section{MARSELLA 1940-1941. UN PARÉNTESIS DE ESPERA}

A mediados de octubre de 1940 los Breton llegaron a Marsella, encontrándose con otros surrealistas como Victor Brauner, Óscar Domínguez, Jacques Herold y Wifredo Lam. En torno a Breton, que se alojaba en la Villa Air Bel, se reunían para mantener el ánimo pese a las penurias y el frío -ese invierno fue especialmente duro-, y realizar una obra de grupo única, el «Tarot surrealista». Este hecho se ha comentado en más de una ocasión como si los surrealistas estuvieran alojados en villa Air Bel y la creación del Tarot fuera una diversión, pero lo cierto es que sólo Breton y Victor Serge se alojaban allí y los demás sobrevivían como podían. Óscar Domínguez, de hecho, vivía en una granja cercana y la imposibilidad de lograr un visado era algo que le angustiaba. Además, en ese invierno de 1940 dos elementos habían convertido su vida en un drama: la acromegalia, enfermedad que deformaría su rostro, y de la que toma plena conciencia cuando se autorretrata como toro en Tête de taureau (1941), y la culpa en el accidente con Victor Brauner, cuando éste perdió un ojo a causa de la botella lanzada por Domínguez contra Esteban Francés. Acerca de este accidente, Sarane Alexandrian escribió:

En efecto, la noche del 27 al 28 de agosto de 1938, (Óscar Domínguez) fue el responsable del accidente en que perdió un ojo su amigo Victor Brauner... Pierre Mabille, en su artículo L'oeil du peintre, publicado inmediatamente después (Minotaure, n. $^{\circ} 11-12$, mayo de 1939), reveló que hacía mucho tiempo que Brauner había predicho este accidente en un sinnúmero de pinturas ${ }^{10}$.

El artista canario quedó conmocionado por el suceso y, pese a recuperar la amistad de Victor Brauner, nunca logró superar el recuerdo de aquel momento ${ }^{11}$. Pero la estancia en Marsella no duró mucho, y el 25 de marzo de 1941 los Breton embarcaron en el Capitain Paul Lemerle rumbo a la Martinica. Victor Serge y su familia también iban en ese viaje, aunque otros no pudieron escapar. Óscar Domínguez regresó a París.

\section{PARÍS 1943. MAUD BONNEAUD Y LOS RESTOS DEL SURREALISMO}

Durante el invierno de 1940, Maud continuó en Poitiers, donde acabó sus estudios en 1941. La elección del tema que escogió para su licenciatura no deja de ser sorprendente: Procedimientos del terror y psicología del miedo en la novela llamada gótica inglesa, desde Ann Radcliffe a Mathew Lewis. El título nos indica varias

10 Alexandrian, Sarane: «El hombre de la fatalidad», en Óscar Dominguez. El surrealismo volcánico, París, 2006. p. 63.

${ }_{11}$ Guillon, Jean Marie: «La villa Air Bel», en Varian Fry. Mission Americaine de sauvetage des intellectuels anti-nazis, Marseille 1940-42. Actes sud 18 mars-30 juin 1999, Marsella, 1999. p. 42. 
cuestiones que marcarían su vida: su fascinación por la literatura, su educación anglófila y, fundamentalmente, el valor de afrontar un trabajo que se adentraba en los caminos del Surrealismo aunque, según sus propias palabras, no encontró información suficiente para llevarlo a cabo.

Reconstruir el tiempo entre 1941 y 1943, año en que llegó al París ocupado, es difícil, y aún más difícil explicar por qué Maud tomó esa decisión. Lo cierto es que ella quería encontrar los restos del Surrealismo, afirmación compartida por quienes la conocieron. Sin embargo, el hecho de que viajara desde Limoges a la capital en plena ocupación, no deja de ser desconcertante ${ }^{12}$. Pero la decisión estaba tomada $y$, ante la negativa de sus padres a ayudarla, vendió todo lo que tenía -libros de buena edición, algunas piezas dentales de oro de herencia familiar y alguna joya-. La despedida de sus padres fue fría y desoladora ${ }^{13}$, pues éstos no entendían qué movía a su hija a viajar al París ocupado ${ }^{14}$. Un amigo de la familia, que Maud oculta bajo las iniciales J.J., la ayudó en su traslado. A su llegada se instaló en un hotelito de Saint Germain des Prés, iniciándola J.J. en el mercado negro de libros, algo común en esos tiempos ${ }^{15}$. En la capital contaba con la amistad de Laurance Iché, la poeta surrealista autora del libro Au fil de vent, ilustrado por Óscar Domínguez. A través de ella, Maud conoció a Dina Vierny, entonces modelo de Aristide Maillol y más tarde galerist ${ }^{16}$, siendo ella quien, en junio de 1943, le presentó a Óscar Domínguez en el Café Select.

El pintor, que pese a su apariencia monstruosa era un seductor incansable, no dudó un instante al ver a Maud. Ella misma lo relataba con mucho humor:

Fue Dina Vierny quien me presentó a Domínguez en el café Select. Ahí estaba, elegante y monstruoso. Se acercó a mí y me dijo: «Tú eres la niña saltamontes y me casaré contigo». Y yo, pobre limusina, me lo creí17.

12 Ocupación nazi de Francia. Años negros y amargos. Empecé una tesina ambiciosa: Procedimientos del terror y psicología del miedo en la novela llamada gótica inglesa, desde Ann Radcliffe a Monk Lewis. Falta de documentación en una Europa deshecha. Marché a París en 1943, en busca de lo que podía quedar allí del surrealismo. Ver Gaviño de Franchy, Carlos: «Maud (Bonneaud) Westerdahl. Biocronología», en Maud y Eduardo Westerdahl. 2 miradas del siglo 20, p. 16.

13 Westerdahl, Maud: nota personal inédita, sin fecha. Madrid: Archivo Hugo Westerdahl, consultado el 17 de mayo 2016.

${ }_{14}$ Ambos estaban comprometidos con la Resistencia francesa; de hecho, su padre, Arsène Bonneaud, sería detenido por los nazis un año más tarde y murió en el campo de concentración de Buchenwald el 2 de marzo de 1944. Ver Villegier, Jacques: "Arsène Bonneaud». Cahiers Robert Margerit. Histoire 1939-1940, XIV-16, 2010, pp. 212-218. http://www.robert-margerit.com/cahiers/ cahier14/Cahier-XIV-16.pdf.

${ }^{15}$ Westerdahl, Maud: nota personal inédita, sin fecha. Madrid: Archivo Hugo Westerdahl, consultado el 17 mayo 2016.

${ }^{16}$ Maud expuso sus esmaltes en 1947 en la Galerie Dina Vierny y su obra figuraba entre los fondos permanentes de la misma.

17 Westerdahl, Maud: nota personal inédita, sin fecha. Madrid: Archivo Hugo Westerdahl, consultado el 17 mayo 2016. 
Este encuentro fue el comienzo de una historia de amor intensa y turbulenta. Domínguez, por aquel entonces muy cercano al círculo de Picasso, quedó fascinado por la inteligencia y la energía de Maud, presentándole «una bella mañana» al artista malagueño. De esas visitas Maud hablaría muchos años más tarde:

Su casa era un centro vivo de la resistencia intelectual en contra del lema: cuando oigo la palabra cultura saco la pistola. Picasso hablaba o escuchaba, enseñaba sus últimas obras. El aire era a la vez grave y ligero. Uno se sentía vivir en la inteligencia libre, pero sin pomposidad ${ }^{18}$.

La amistad de Maud con el pintor duró toda su vida, y siempre escribió sobre él con admiración y afecto: «Sobra decir que el taller de Picasso recibía la visita de muchos artistas que él ayudó con infinita paciencia, moral y económicamente» ${ }^{19}$.

Como afirma Dolores Fernández Martínez ${ }^{20}$, Picasso era el puerto seguro en torno al que se agrupaban los artistas españoles, tanto los más politizados como los que no lo estaban. Entre los segundos, el apátrida Óscar Domínguez, pese a su escaso interés por la política, tenía gran afinidad con los artistas que participaban en la revista La main à plume, inspirada por André Breton y alentada económicamente por Pablo Picasso.

La amistad de Maud con Picasso se puede constatar a través de los textos de Maud, las cartas de Óscar Domínguez a Eduardo Westerdahl ${ }^{21}$, las que intercambiaron Maud y Óscar Domínguez con Picasso (nueve de ellas en los fondos Picasso) ${ }^{22}$ y las fotografías de Maud y Picasso compartiendo espacio con la complicidad de los viejos amigos ${ }^{23}$.

En esos años difíciles de la ocupación alemana en París, la relación de Maud y Óscar Domínguez se afianzó rápidamente. Al mismo tiempo que se consolidaba su relación de pareja, empezaron juntos a trabajar de forma experimental con esmaltes. Es muy posible que éstos fueran inspirados por la tradición artesanal de Limoges,

18 Westerdahl, Maud: nota personal inédita sin fecha. Madrid: Archivo Hugo Westerdahl, consultado el 17 mayo 2016.

19 Westerdahl, Maud (2005): «Picasso, persona», en Maud y Eduardo Westerdahl. 2 miradas sobre el siglo 20, opus cit., p. 45.

${ }^{20}$ Fernández Martínez, Dolores: «Complejidad del exilio artístico en Francia», en Migraciones y exilios. Cuadernos AEMIC Asociación para el estudio de los Exilios y Migraciones Ibéricos Contemporáneos 2-2005, pp. 33-34. En http//www.aemic.org/ediciones/9.

${ }^{21}$ Domínguez, Óscar: 1940-1957. Cartas a Eduardo Westerdahl, Tenerife: Fondo Westerdahl, AHPT, Gobierno de Canarias. D.254, D.255, D.257, D.259, D.263, D.265 y D267.

22515 AP. Fonds Picasso. Serie C, Correspondance Génerale, Inventaire Index.2005, http:// www.archivesnationales.culture.gouv.fr/chan/chan/fonds/picassohtml/d0e95.html. Consultado el 27 de octubre 2016.

23 Westerdahl, Eduardo (1955-1968): Fotografías de Maud y Pablo Picasso. Tenerife: Fondo Westerdahl, AHPT, Gobierno de Canarias, n.os 948, 951, 952, 954, 956, 960, 962, 963, 965 , 966, 968, 972, 973, 975, 976, 971, 978, 1005, 1008, 4034, 4811 у 4812. 
cosa que Maud deja entrever en una entrevista años más tarde ${ }^{24}$, aunque su sistema fue desde el inicio muy experimental y autodidacta. Su hijo Hugo Westerdahl confirma que al principio el procedimiento era muy intuitivo y que Óscar y Maud estropearon muchas pruebas, pues no contaban con un horno adecuado y la idea original era utilizar elementos de desecho ${ }^{25}$. Tras esta etapa inicial, Maud continuó con los esmaltes, mientras que Óscar siguió pintando. A lo largo de su vida los esmaltes de Maud alcanzarían una gran belleza y pese a la dureza del trabajo continuó haciendo joyas y pequeńas piezas de carácter escultórico hasta la década de 1970.

Óscar Domínguez, pese a la estabilidad que inicialmente había encontrado en Maud y a su intensa actividad artística, comenzaba a presentar graves problemas mentales, agravados por el abuso del alcohol. Su adicción empeoraba cada día y la propia Maud tuvo que ingresarlo en dos ocasiones en un centro psiquiátrico. De hecho, sus amigos eran testigos de su carácter cada vez más difícil, tal y como afirmó Laurance Iché en una entrevista concedida en 2005:

Fue un momento de depresión, sin duda (se refiere al año de su muerte). Padecía de acromegalia, podía terminar loco de remate. Por eso decía Maud que era peligroso vivir con él ${ }^{26}$.

\section{LONDRES 1947. LA AMISTAD CON VALENTINE PENROSE}

En 1947, Maud y Óscar Domínguez expusieron en Londres, con ocasión de lo cual Domínguez escribió a Eduardo Westerdahl una larga carta, en la que encontramos varias claves de su vida y su relación con Maud:

Como verás estoy en Londres hasta fines de este mes. He venido representando a los pintores españoles de la Escuela de París y estoy corrigiendo a los alumnos de esta academia (...).

Mi amistad con Picasso se afirma cada día más. Me he retirado del grupo surrealista pues creo que este movimiento ha muerto por inercia (...). A causa de mi actitud Breton está enfadado por el momento. Ya comprenderás todo esto cuando veas mis cuadros recientes (...).

Tengo una mujer muy guapa y muy interesante que se llama Maud ${ }^{27}$.

${ }^{24}$ Prats de Laplace, María Teresa: «Hablando con Maud Bonneaud de Arte y Moda», Revista Mujeres en la Isla, n. ${ }^{\circ}$ 5, Las Palmas de Gran Canaria, 1954.

${ }^{25}$ Entrevista con Hugo Westerdahl. Madrid, 28 marzo de 2017.

${ }^{26}$ Utrera, Federico: «Laurance Iché. Entrevista». Edición Domingo. Canarias 7, 5 junio 2005.

27 Domínguez, Óscar: Carta a Eduardo Westerdahl, 12 abril 1947, Fondo Westerdahl, AHPT, Tenerife, Gobierno de Canarias, D 256. 


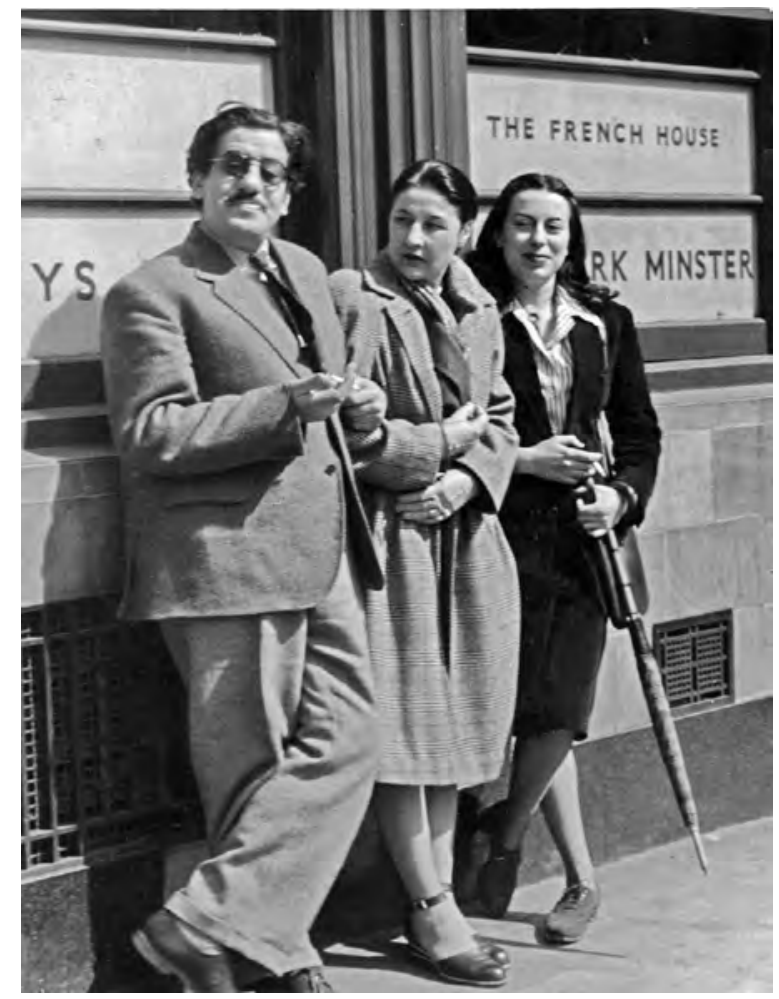

Fig. 1. Marie Louise Richard: Óscar Domínguez, Valentine Penrose y Maud Bonneaud, Londres, 1947. Reproducida en Eduardo y Maud Westerdahl, 2 miradas del siglo 20.

Durante su estancia londinense disfrutaron de la compañía de Valentine Penrose, con quien posan en una fotografía delante de The French House ${ }^{28}$.

La amistad con Valentine Penrose sería constante en la vida de Maud y parte de la inspiración bizantina y orientalizante de sus esmaltes tuvo que ver con ella. De los frecuentes viajes de Maud a Inglaterra para visitar a su amiga dan cuenta las numerosas entradas en el libro de invitados de Fairley Farm, que conocemos gracias a Antony Penrose, director del Museo Penrose e hijo de sir Roland Penrose y Lee Miller, además de la correspondencia entre ambas y de los poemas dedicados por Valentine a Óscar Domínguez y a la isla de Tenerife. Años más tarde, ya en la década

${ }^{28}$ Richard, Marie Louise: fotografía de Maud Bonneaud, Valentine Penrose y Óscar Domínguez, Londres, 1947. Reproducida en Eduardo y Maud Westerdahl, 2 miradas del siglo 20, p. 55. 
de los cincuenta, cuando Maud se casó con Westerdahl y se fue a vivir a Tenerife, Valentine siguió visitándola con asiduidad ${ }^{29}$.

\section{1947 PARÍS. LOS DOS QUE SE CRUZAN Y LA INFLUENCIA DE MAUD}

Tras el viaje a Londres, Maud ayudó a ordenar los textos poéticos de Domínguez, publicados bajo el título de Les deux qui se croisent. En este libro de poemas encontramos la influencia de los rosacruces que aquél había absorbido a través de la lectura de Les noces chimiques. La presencia de Maud es esencial, pues no sólo recibe la dedicatoria del libro, sino que Domínguez la describe con frecuencia, evocándola unas veces como «la niña saltamontes» y otras como la creadora poderosa que, a través del fuego, logra realizar joyas de gran belleza. Un ejemplo de ello es este poema:

Marcoussis Rosecroix et la ligne brisée

Deux dates deux perspectives et croyez-moi

Le grand nez triangulaire et violet du feu.

Maud téléphone émail feu du four

Grande chaleur temperature des températures

Voilá la grand Alchimie voilá la grande ilusion

La grande Maud descendant l'escalier de service

Avec le plus grand diamant de l'histoire ${ }^{30}$.

Acerca de esta obra, en 1978 Maud escribió:

En la época de la más intensa vida de los dos, Óscar Domínguez terminaba de leer Las bodas quimicas de Christian Rosencreuz de Basile Valentin, libro altamente apreciado por André Breton por su contenido esotérico y su poesía ${ }^{31}$.

Maud Westerdahl, siempre discreta, no explicaba en el texto lo que ahora podemos desvelar: que en realidad, la lectura que inspiró a Domínguez se la había proporcionado ella, alentada por la carta escrita por Breton en1940, ya citada:

Que peut-on lire à votre avis? Qu'avez vous remarqué surtout dans le choix de textes du "Miroir du merveilleux"? Moi, le passage des "Noces chimiques"32.

${ }^{29}$ Orban, Severine Aline : Avis de Recherche: Valentine Penrose, oeuvre et vie d'une artiste surréaliste. Louisiana State University: LSU Digital Commons. LSU Doctoral Dissertations, 2014, pp. 127 y 167.

30 Domínguez, Óscar. Les deux qui se croisent, París, 1947, p. 27.

31 Westerdahl, Maud. «Óscar Domínguez o la convivencia con los mitos», en Los dos que se cruzan. Óscar Dominguez (1947), ed. Carlos Gavińo de Franchy, La Laguna, Tenerife, 1978, p. 21.

32 Breton, Andre: Lettre à Maud, p. 9. 


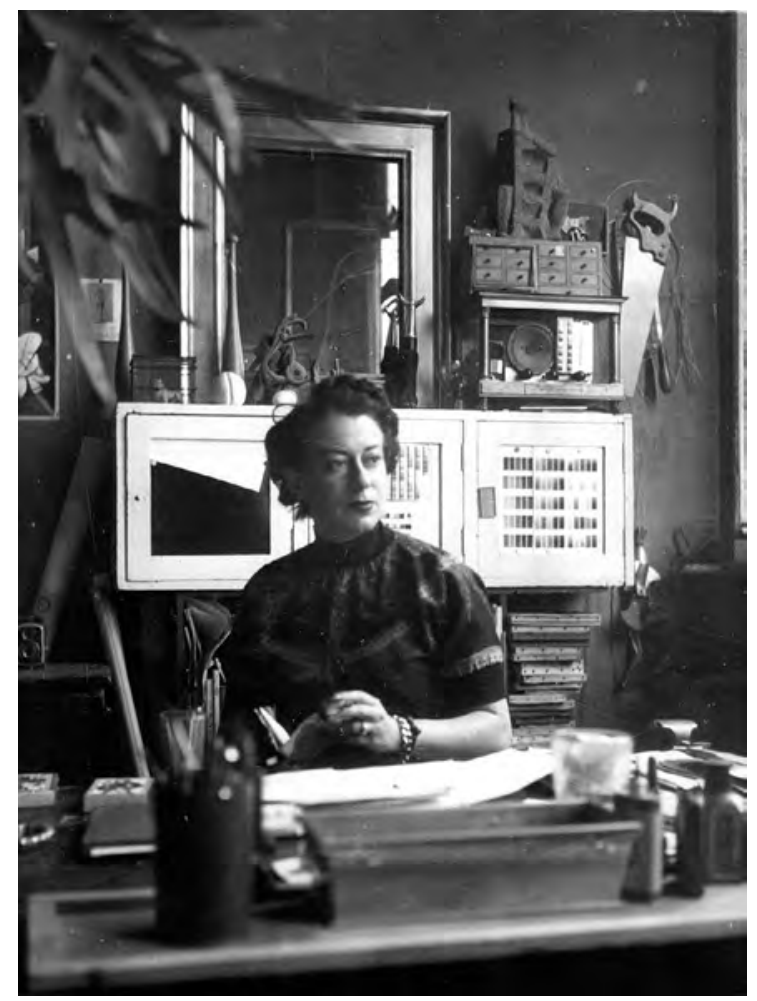

Fig. 2. Autor desconocido: Maud Bonneaud-Domínguez en el estudio de Óscar Domínguez, París, 1950. Archivo Hugo Westerdahl.

\section{PARÍS-LIMOGES 1944-1951. MAUD BONNEAUD Y EL INICIO DE L'ART BRUT}

En 1944 Maud recibió de Gaston Chaissac el texto Peinture rustique moderne, haciéndoselo llegar a René Rogerie, director de la revista Centres, con quien mantenía una estrecha amistad. En el texto Chaissac formulaba su defensa de una pintura primitiva, despojada de adornos, lo que se puede considerar como parte inicial del proceso de L'Art Brut ${ }^{33}$. La importancia que Maud tuvo en este asunto como transmisora y alentadora de esta publicación consta también en otro texto:

33 Bounoure, Gilles: "Chaissac, Dubuffet et la question de L'Art Brut», en Revue Contretemps, n. ${ }^{\circ} 18$, septiembre 2003. https://www.ensemble-fdg.org/content/chaissac-dubuffet-etla-question-de- $\%$ C2\%AB-1\%E2\% $80 \% 99$ art-brut-\%C2\%BB-ou-autre. Consultado el 16 mayo 2017. 
Alerté par Maud Bonnaud, épouse du peintre Óscar Domínguez ${ }^{34}$, René Rougerie découvre Gaston Chaissac dans la revue Pierre à Feu, publiée par Aimé Maeght. Il lui publie "Cinq contes» ainsi qu'un texte fondateur dans lequel l'auteur se place dans la sphère artistique, avant même le manifeste de l'art brut publié en 1949 avec lequel il préfère prendre de la distance ${ }^{35}$.

Maud estuvo siempre alerta para descubrir y apoyar nuevos talentos. De hecho la encontramos también relacionada con un pequeño y selecto grupo de artistas e intelectuales afincado en Limoges, ciudad que visitaba con frecuencia. Ahí se reunían en casa del fotógrafo Izis Biedermans, quien realizó varios retratos memorables de Maud. En una carta dirigida a Sarane Alexandrian, Raoul Hausmann subraya la presencia de la "crema intelectual de Limoges» en una velada celebrada en casa de Izis (Biedermans) en septiembre de 1945. Algunos datos permiten reconstruir el encuentro y los participantes. Allí estaban «Maud Westerdhal (sic), acompañada del pintor Óscar Domínguez, su hermana (Dood Bonnaud), Maître Charlet, los dos hermanos Rougerie, Raoul Hausmann, su mujer Hedwig y Marthe Prévost, además de "seis u ocho personas"... Maud Westherdal (sic) compara la soirée con un happening»"

En los años posteriores a la guerra, la ambivalencia de Óscar Domínguez ante el Surrealismo era notable. Sin embargo, el afecto que sentía por Breton era profundo y, posiblemente desconcertado ante su silencio - pues Breton había regresado de su exilio americano en 1946-, le pidió a Maud que le escribiera una carta conciliadora:

Mon cher André / Óscar m’a dit “Toi que tu es dans la littératur”, écris à André que nous attendons toujours son coup de téléphone. / Nous sommes en effet extrêmement impatients de vous revoir. Nous pensons que c'est important. Tant de bruits circulent, tant d'histoires ont été inventées, qu'Óscar tiendrait beaucoup à tirer cela au clair avec vous ${ }^{37}$.

Pero a pesar de la respuesta de Breton y a su reencuentro, la relación de Domínguez con Paul Éluard hizo que la amistad se rompiera. Maud -no obstante- mantuvo siempre una elegante discreción al respecto, afirmando su admiración por Breton, confirmada por el texto escrito en homenaje al poeta en Gaceta de las artes en $1966^{38}$.

${ }^{34} 1945$ es el año que por error se ha dado como el de su boda con Óscar Domínguez, pero la fecha correcta es 11 marzo 1948. Maud y Óscar se divorciaron el 21 de octubre de 1954.

35 Aвadie, Daniel: Entre plume et pinceau, la relation Chaissac et Dubuffet, 2014. http:// www.gaston-chaissac.org/revue-centre-rougerie-rustique-moderne.htm. Consultado el 16 mayo 2017.

36 Jaunasse, Delphine: Raoul Hausmann: l'isolement d'un dadä̈ste en Limousin, Limoges, 2002. pp. 240-241

37 Sebbag, Georges: «Le souvenir de l'avenir», Congreso Internacional «Surrealismo siglo XXI, tomo I, ed. Domingo Luis Hernández, La Laguna, Tenerife, 2006, pp. 288-297.

${ }^{38}$ Pérez Minik, Domingo: Entrada y salida de viajeros, Santa Cruz de Tenerife, 2008, 2. ${ }^{\mathrm{a}}$ ed. pp. 43-44. 


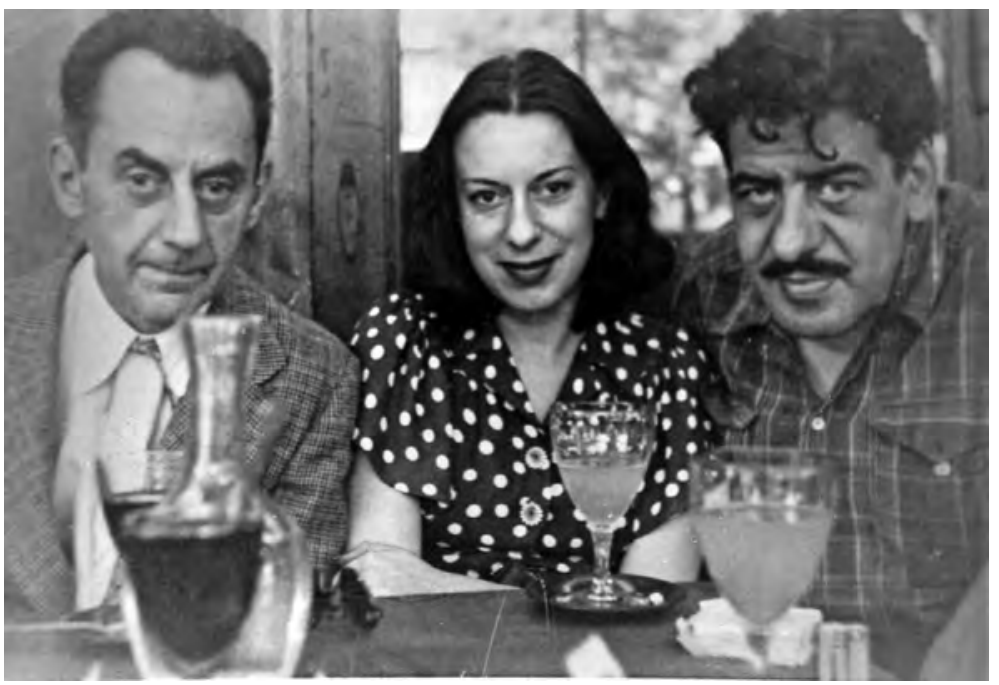

Fig. 3. Autor desconocido: Man Ray, Maud Bonneaud y Óscar Domínguez, París, 1947, Archivo Hugo Westerdahl.

\section{1951. PARÍS-TENERIFE. LA MEMORIA DEL SURREALISMO}

En 1950, Maud y Óscar Domínguez se separaron, y dos años más tarde fue Domínguez quien le presentó a Eduardo Westerdahl. Éste, que había dirigido la revista Gaceta de arte (1932-1935) y había impulsado en Tenerife la II Exposición Internacional del Surrealismo, quedó fascinado por la personalidad de la artista, invitándola a exponer sus esmaltes en Tenerife en 1953. Tras este primer viaje y una intensa correspondencia, Maud se divorció de Domínguez, contrayendo matrimonio con Eduardo Westerdahl en noviembre de 1955.

Instalada en Tenerife, desarrolló una intensa actividad como artista -exponiendo sus esmaltes en Canarias, Madrid y Barcelona- y como crítica de arte y comisaria de la exposición homenaje a Óscar Domínguez que tuvo lugar en el Museo de Bellas artes de Santa Cruz en 1968. Años más tarde, su amistad con los Penrose sería esencial para llevar a cabo la I Exposición Internacional de Escultura en la Calle. Su papel como transmisora de ideas y su vida anterior como Maud Bonneaud quedó en el olvido, o al menos eso es lo que se recoge del catálogo de la exposición de Óscar Domínguez de 1996, donde sólo es citada en dos ocasiones. Un olvido que empezó a ser subsanado gracias a la exposición Eduardo y Maud Westerdahl. 2 miradas del siglo 20, celebrada en 2005. No obstante, en el archivo Pérez Minik de Santa Cruz de Tenerife encontramos varias cartas que permiten aventurar que ella, pese al silencio que guardó sobre su vida pasada, mantuvo viva la amistad con los surrealistas que habían marcado su vida, creando unos lazos profundos con Domingo Pérez Minik y Pedro García Cabrera, ambos redactores de la mítica revista Gaceta 


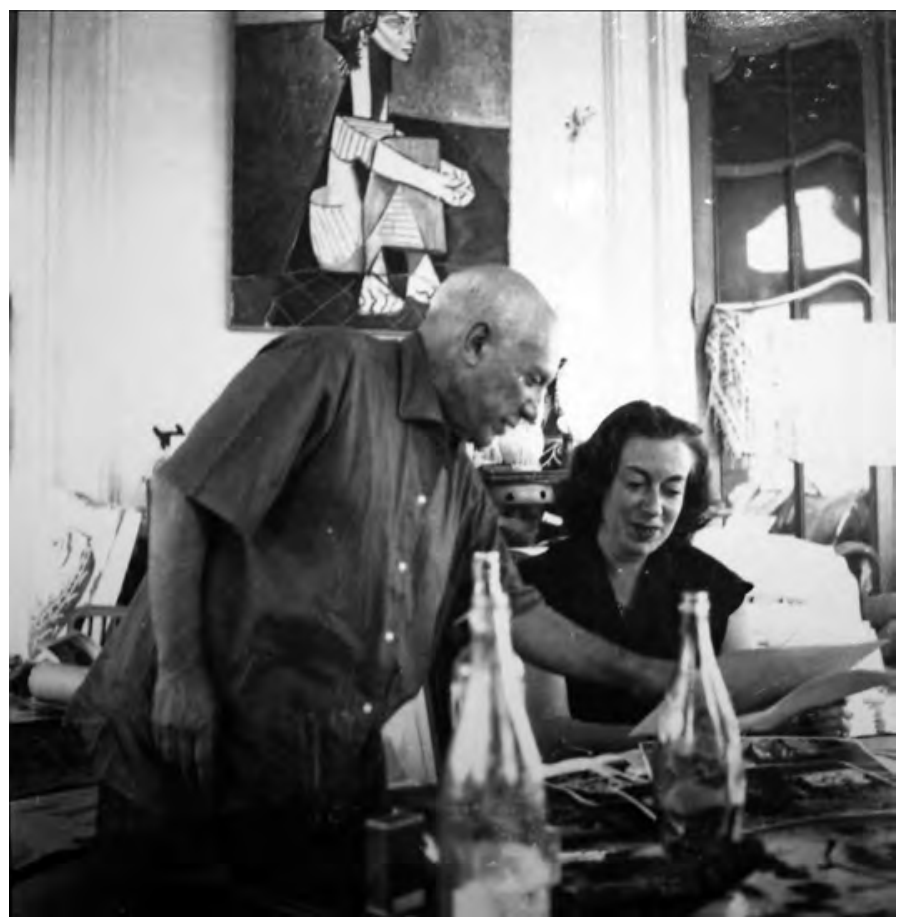

Fig. 4. Eduardo Westerdahl: Picasso y Maud en La Californie, 1957, Fondo Westerdahl, Gobierno de Canarias.

de arte y depositarios de la memoria del Surrealismo. De su actividad incesante y de la actitud abierta a la Modernidad que permaneció siempre en Maud, tanto fuera Bonneaud, Domínguez o Westerdahl, dan constancia estas palabras, escritas desde el que fue su último domicilio en Madrid.

Veo mucho, claro está, a Martin (Chirino), Elvireta (Escobio, viuda del pintor Manolo Millares), mi íntima amiga francesa Laurance Viola (Laurance Iché, casada en segundas nupcias con el pintor español Manuel Viola) y además de exposiciones y reuniones tengo además que rechazar invitaciones. Evidentemente los dos apellidos que llevé (Domínguez y Westerdahl) no el mío propio, abren muchas puertas en el mundo artístico e intelectual ${ }^{39}$.

ReCibido: 11-10-2017, ACEPTADO: 10-04-2018

39 Westerdahl, Maud: carta a Domingo Pérez Minik, 18 de febrero de 1988, Archivo Pérez Minik, Santa Cruz de Tenerife. 


\section{FUENTES PRIMARIAS}

Archivo Histórico Provincial Tenerife (AHPT). Fondo Westerdahl:

Domínguez, Maud: correspondencia con Eduardo Westerdahl.

Domínguez, Óscar: correspondencia con Eduardo Westerdahl.

Westerdahl, Eduardo (1955-1968): fotografías de Maud y Pablo Picasso.

Archivo Hugo Westerdahl Madrid (AHWM):

Westerdahl, Eduardo: correspondencia con Maud Domínguez.

Westerdahl, Maud: notas personales.

AA. VV.: fotografías de Maud, Cortesía Hugo Westerdahl.

Archivo Pérez Minik, Santa Cruz de Tenerife (APM):

Westerdahl, Maud: correspondencia con Domimgo Pérez Minik.

Entrevista con Carlos Gaviño de Franchy. Tenerife, 17 de julio 2006.

Entrevista con Hugo Westerdahl. Madrid, 28 de marzo 2017.

Entrevista con Antony Penrose. East Sussex, 2 de julio 2017. 